\title{
O TWITTER COMO DISPOSITIVO DE MEDIAÇÃO DA INFORMAÇÃO EM PERÍODOS ELEITORAIS: ANÁLISE DAS ELEIÇÕES DE 2014 EM ALAGOAS
}

\author{
TWITTER COMO INSTRUMENTO DE MEDIACIÓN DE LA \\ INFORMACIÓN EN PERIODOS ELECTORALES: \\ ANÁLISIS DE LAS ELECCIONES DE 2014 EN ALAGOAS
}

\author{
Ronaldo Ferreira de Araújo*
}

\begin{abstract}
RESUMO:
Introdução: O caráter relacional e colaborativo proporcionado por plataformas online e mídias sociais oferecem novos elementos para se (re)pensar a comunicação política sobretudo em seus aspectos de mediação da informação. Objetivo: analisar a apropriação do Twitter em seus aspectos interativos e conversacionais enquanto dispositivo de mediação informacional entre eleitores e os principais candidatos ao governo do estado de Alagoas nas eleições de 2014. Metodologia: Pesquisa exploratória com coleta e sistematização dos dados realizadas no período de 01/07/2014 a 05/10/2014 por meio do software de monitoramento de métricas de mídias sociais, BrandCare. O universo empírico de 11.619 mensagens é analisado segundo uma abordagem combinatória da Análise de Redes Sociais e da Conversação Mediada por Computador, e descrito por sua distribuição geográfica, temporal, por categorias, bem como em seus aspectos de interatividade e conversação. Resultados: As mensagens postadas por eleitores representam $89,03 \%$ do total e dos candidatos $10,96 \%$. No total foram identificados 8.101 usuários, dos quais $31 \%$ são mulheres e $69 \%$ são homens. O posicionamento mais frequente dos usuários é de adesão à campanha e de apoio aos candidatos e os assuntos de maior recorrência das mensagens são saúde, educação e combate à violência. A rede é fragmentada. Não houve prolongamento das interações e poucas obtiveram reciprocidade e persistência. Conclusões: Se ainda não há diálogos no Twitter certamente não é por falta de interesse dos eleitores, pois suas menções aos candidatos revelam que eles se fazem presente no ambiente. Resta saber por que as campanhas não conseguem manter perfis mais dialógicos para dar ressonância à participação política.
\end{abstract}

Palavras-chave: Participação Política. Mediação da Informação. Twitter. Conversação Mediada por Computador. Análise de Redes Sociais.

* Doutor em Ciência da Informação (UFMG). Professor do Curso de Biblioteconomia, Universidade Federal de Alagoas (UFAL). E- mail: ronaldo@gmail.com

Inf. Inf., Londrina, v. 22, n. 2, p. 420 - 436, maio/ago., 2017. http:www.uel.br/revistas/informacao/ 


\section{INTRODUÇÃO}

O amplo uso da internet e dos sites de redes sociais por candidatos e eleitores marca cada vez mais a entrada das eleições do país nos moldes de uma cultura digital participativa, despertando o interesse de inúmeros pesquisadores e grupos de pesquisa que analisam as novas mídias enquanto mediadoras dos processos de participação política.

Quando vistos no contexto das campanhas online esses novos ambientes digitais possuem potencial democrático no estreitamento das relações entre os cidadãos e políticos por meio de uma mediação da informação expressa em uma comunicação dialógica.

Pesquisas que investigaram o uso dos sites de redes sociais nesse contexto analisam, com maior frequência, a apropriação e o uso feito pelos candidatos (comportamento e desempenho), que na sua maioria, no quesito interação e responsividade, revela um perfil de utilização distante da almejada proximidade com o eleitor.

Permanece ainda uma lacuna, quem vem sendo timidamente discutida (ARAÚJO, 2014a,b) no que se refere à análise da relação entre os atores desse processo, e que de preferência a contemple para além dos dados quantitativos dessa interação, e alcance o nível da conversação estabelecida considerando as falas dos sujeitos.

O presente artigo pretende contribuir com essa segunda questão dedicando-se aos aspectos da rede de interações e a conversação, estabelecidas no Twitter, durante as eleições de 2014, entre os principais candidatos ao governo do estado de Alagoas e os cidadãos/eleitores.

\section{MEDIAÇÃO DA INFORMAÇÃO E PARTICIPAÇÃO POLÍTICA NO TWITTER}

O caráter relacional e colaborativo proporcionado por plataformas online oferecem novos elementos para se (re)pensar a comunicação política sobretudo em seus aspectos de mediação. Campanhas políticas nesses ambientes digitais possibilitam ao eleitor, além de obter informação sobre

Inf. Inf., Londrina, v. 22, n. 2, p. 420 - 436, maio/ago., 2017. http:www.uel.br/revistas/informacao/ 
Ronaldo Ferreira de Araújo

O twitter como dispositivo de mediação da informação em períodos eleitorais: análise das eleições de 2014 em Alagoas

questões relativas ao seu candidato, o poder de se engajar no debate político e na prática participativa democrática, tendo uma formação diferenciada sobre as questões políticas de seu interesse.

Tal aproximação pode inclusive fornecer uma ideia de accountability eleitoral (MAIA, 2012; MENDONÇA; CAL, 2012), não aquela formal e institucionalizada, mas a que, de algum modo, também exige 'prestação de conta' e coloca o eleitor como avaliador e julgador do comportamento do candidato e de suas propostas.

Talvez fosse ainda mais adequado considerar tratar-se de uma 'accountability discursiva' (MENDONÇA, 2008; MENDONÇA; CAL, 2012) na qual as pretensões de representação seriam permanentemente testadas por meio do debate público (SAWARD, 2010) e contínua comunicação dialógica e responsiva (DRYZEK; NIEMEYER, 2008; MAIA, 2012).

De acordo com Araújo (2014b) dentre as mídias sociais existentes o Twitter tem ganhado destaque em diversas pesquisas nas quais o microblog pode ser considerado um dispositivo de mediação da informação (PIERUCCINI, 2013), seja como provimento de informação e mesmo de oferta de mecanismos de participação (JAMIL; SAMPAIO, 2011).

Para o autor

Ao citar um candidato no Twitter, o eleitor explora o ideal de mediação informacional cívica do dispositivo e expressa seu interesse em estabelecer diálogo com os agentes políticos, e ao responder as menções recebidas o candidato confirma o uso dialógico dessas plataformas na participação democrática. Nessas trocas informacionais temos um percurso que vai dos aspectos interativos aos conversacionais, que por sua vez, demandam reflexões teóricas e metodológicas para os estudos das campanhas online (ARAÚJO, 2014b, p.1463).

Em outro trabalho Araújo (2014a) propõe o debate do tema em um percurso teórico-metodológico por meio de abordagens combinadas centradas na Conversação Mediada por Computador (CMC) e na Análise de Redes Sociais (ARS). Segundo o autor a proposta contribui para o mapeamento da rede e da conversação que se forma em torno do engajamento cívico em períodos eleitorais e "favorece o rompimento da centralização, que geralmente

Inf. Inf., Londrina, v. 22, n. 2, p. 420 - 436, maio/ago., 2017. http:www.uel.br/revistas/informacao/ 
tem foco no desempenho dos agentes políticos, dando uma visão distribuída e de uso dialógico do microblog" (ARAÚJO, 2014a, p.703).

As práticas sociais que decorrem dos valores construídos e percebidos por usuários do Twitter costumam ser divididas em duas categorias: (a) aquela de conteúdo - refere-se à relevância e influência das informações publicadas, na busca de levá-las a um determinado grupo e a (b) de conversação relaciona-se aquelas que visam a iniciar um diálogo, uma troca de informações, e por sua vez, espaço de conversação (FRAGOSO; RECUERO; AMARAL, 2011). Essas categorias seriam relacionadas aos valores dos tweets publicados, tanto como 'ferramenta informativa' quanto como 'ferramenta social' (ARAÚJO, 2014a).

Um dos elementos práticos mais importantes do estudo das redes sociais na internet atualmente são os modos de mapeamento dessas redes (ARAÚJO, 2014a). O espaço digital permitiu a ampliação das redes sociais e o mais importante, o seu registro (FRAGOSO; RECUERO; AMARAL, 2011) e com isso a possibilidade de serem rastreadas e mapeadas não apenas a rede de interatividade e conversações, mas as próprias conversações em rede.

Os estudos sobre conversação em rede têm contribuído para compreender a mediação da informação expressa nas interações de uma maneira mais qualitativa e apontam o uso do Twitter como ferramenta social. Por meio da conversação, é possível observar elementos diversos da organização e da negociação dos valores que são construídos nas redes sociais. A partir do mapeamento da conversação e seus aspectos, estrutural e semântico, é possível compreender a qualidade das conexões estabelecidas entre os atores, bem como o sentido construído entre os interagentes. De acordo com Recuero (2012, p. 203)

O aspecto estrutural de uma conversação pode ser observado através da análise e negociação dos turnos estabelecidos entre os atores, de onde é possível se depreender a estrutura da rede social. $O$ aspecto semântico auxilia na compreensão do significado das mensagens, de onde é possível depreender o conteúdo dos laços sociais. 
Ronaldo Ferreira de Araújo

O twitter como dispositivo de mediação da informação em períodos eleitorais: análise das eleições de 2014 em Alagoas

QUADRO 1 - Conversação em rede: aspectos a serem mapeados

\begin{tabular}{|cc|}
\hline Aspectos Semânticos & Aspectos Estruturais \\
\hline Conteúdo das interações & Sequenciamento das interações \\
\hline Identificação dos pares conversacionais & Estrutura dos pares conversacionais \\
\hline Negociação dos turnos de fala & Organização dos turnos de fala \\
Reciprocidade & Persistência \\
Multiplexidade & Migração \\
\hline
\end{tabular}

Fonte: Recuero (2012, p. 203).

A partir de tais explanações Recuero (2012) considera cinco aspectos a serem mapeados em uma conversação em rede conforme Quadro 1, no qual temos: conteúdo e sequenciamento das interações - o conteúdo auxilia na percepção do aspecto semântico/discursivo das mensagens na compreensão do que é dito, e como é dito; o sequenciamento é a forma de compreender qual vem antes ou depois e com qual interação é relacionado.

\section{METODOLOGIA}

Trata-se de um estudo exploratório delimitado na análise da conversação em rede e na técnica do incidente crítico, para avaliar a interação entre os candidatos ao governo do estado de Alagoas e os cidadãos/eleitores, nas eleições de 2014. A pesquisa foi desenvolvida a partir do monitoramento de todo o período eleitoral, considerando mensagens postadas no Twitter entre os dias 01 de julho de 2014 a 05 de outubro de 2014.

Os dois principais candidatos e os eleitores que com eles interagiram se constituíram e assim sujeitos da pesquisa e tiveram suas mensagens mapeadas. A coleta, monitoramento e análise foram realizadas a partir do uso da solução BrandCare ${ }^{1}$ que foi parametrizado com consultas que envolvam os tweets das contas oficiais dos candidatos, bem como das menções que eles recebam por “@”, nomes, apelidos e combinações.

1 Software online de monitoramento de redes sociais. Disponível em: < http://socialfigures.com.br/tag/brandcare/ >

Inf. Inf., Londrina, v. 22, n. 2, p. 420 - 436, maio/ago., 2017.

http:www.uel.br/revistas/informacao/ 
Ronaldo Ferreira de Araújo

O twitter como dispositivo de mediação da informação em períodos eleitorais: análise das eleições de 2014 em Alagoas

Para análise e sistematização da rede de conversação adotou-se uma abordagem de análise da conversação em rede (RECUERO, 2012) e da análise de redes sociais, para esta última apoiada no uso do software Gephi².

\section{RESULTADOS: APRESENTAÇÃO E DISCUSSÃO}

De acordo com primeira pesquisa ibope divulgada em agosto de 2014 os dois candidatos com maior intenção de voto foram: Renan Filho (PMDB), na liderança com $29 \%$, Benedito de Lira (PP) com 23\%. A segunda pesquisa divulgada no mês seguinte indicou a permanência das posições de ambos os candidatos. O pemedebista manteve sua liderança subindo para $43 \%$ seu índice de intenção de votos contra $26 \%$ do candidato pepista (IBOPE, 2014).

Ao somar os candidatos aos outros usuários, cidadãos/eleitores, foram identificados 8.101 usuários únicos, dos quais 31\% são mulheres e $57 \%$ são homens. Os perfis institucionais correspondem a $4 \%$ e não identificados $8 \%$.

Em relação ao número de seguidores, todos apresentaram um crescimento: Renan Filho - @RenanFilho_teve aumento de 926 seguidores (tinha 11.010 e chegou a 11.936) e Benedito de Lira - @BiudeLira teve um aumento de 244 seguidores (de 3.631 para 3.875 ).

Foi obtido um total de 11.619 tweets, sendo 6.646 únicos e 4.973 retweets. Além do Brasil (4.192), aparecem mensagens vindas dos Estados Unidos (178), Itália (27), Portugal (19) e Alemanha (19). Do total de mensagens únicas do Brasil, 2.114 são de Alagoas (50,44\%). E dentro do Estado, a capital Maceió alcança 998 (47,20\%) do fluxo. A geolocalização das mensagens com indicação de outros estados do Brasil e outros municípios de Alagoas podem ser vista na Figura 1.

\footnotetext{
2 Plataforma interativa de visualização e exploração de redes e sistemas complexos, grafos dinâmicos e hierárquicos. Disponível em: < https://gephi.org/ >
}

Inf. Inf., Londrina, v. 22, n. 2, p. 420 - 436, maio/ago., 2017. 
FIGURA 1. Distribuição geográfica dos tweets (Brasil x Alagoas).

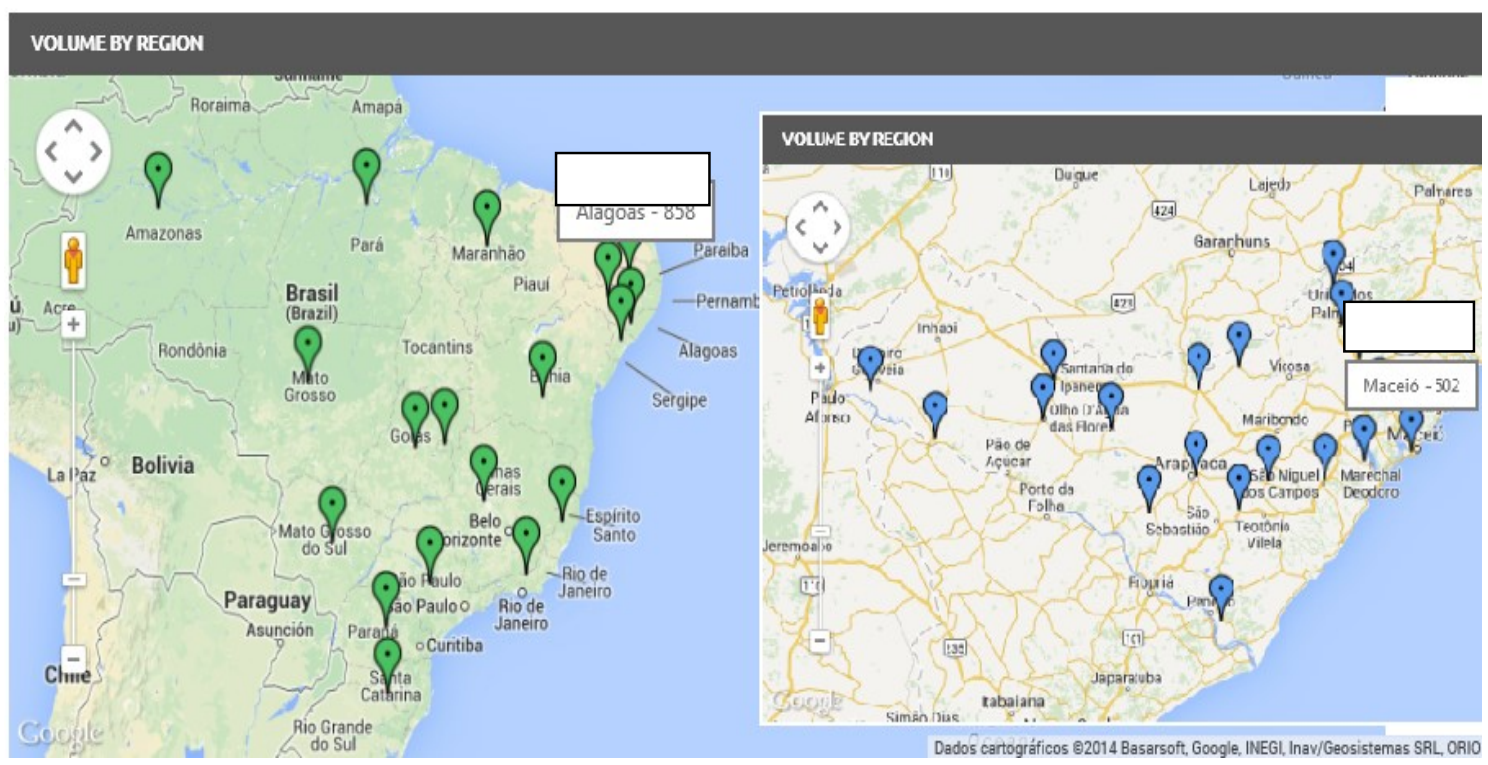

Fonte: Dados da pesquisa.

A distribuição geográfica percebida indica que a maior concentração das mensagens é oriunda de usuários de Maceió com tímida participação de outros municípios, estados brasileiros e outros países. Dispositivos de mediação da informação em ambientes digitais como o Twitter possibilitam a comunicação entre os usuários independente de sua localização, assim, percebe-se os eleitores, críticos ou apoiadores dos candidatos podem interagir com os mesmos, ainda que estejam fora do país ou mesmo do estado onde o pleito ocorria.

O volume acumulado, em termos de (a) número de mensagens enviadas pelos candidatos $+($ b) menções recebidas $+(\mathrm{c})$ retweets realizados confere destaque ao candidato Renan Filho, uma vez que no período analisado o desempenho do candidato supera seu adversário em praticamente todas as semanas, conforme pode ser verificado no Gráfico 1. 
Ronaldo Ferreira de Araújo

O twitter como dispositivo de mediação da informação em períodos eleitorais: análise das eleições de 2014 em Alagoas

GRÁFICO 1. Desempenho por candidato (tweets, mentions e retweets)

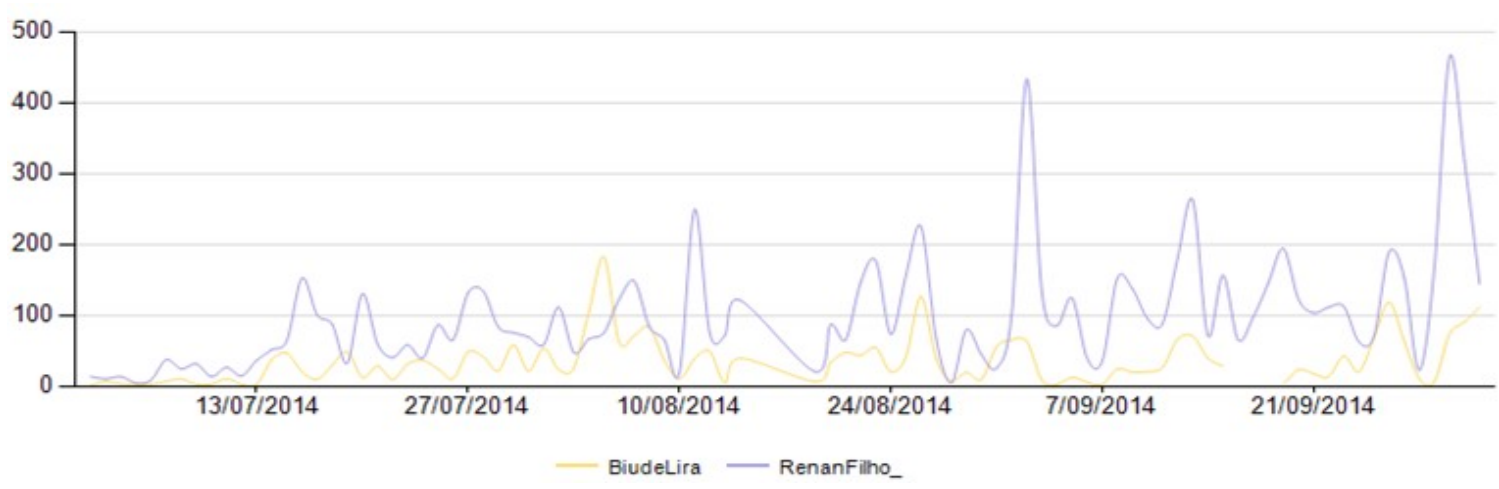

Fonte: Elaboração própria

Em apenas quatro momentos o candidato Renan Filho não lidera e Biu de Lira supera seu desempenho. No dia 19 de julho (32 a 48), nos dias 04 (66 a 104), 05 (75 a 182) e 31 (25 a 75) de agosto. A distribuição das mensagens por horário do dia também foi analisada (Gráfico 2) e oferece uma visão do comportamento informacional de candidatos e eleitores quanto ao perfil de uso que os mesmos fazem do Twitter no que se refere ao período do dia que os mesmos possuem preferências para postar algo na mídia social.

GRÁFICO 2. Distribuição das mensagens por horário do dia

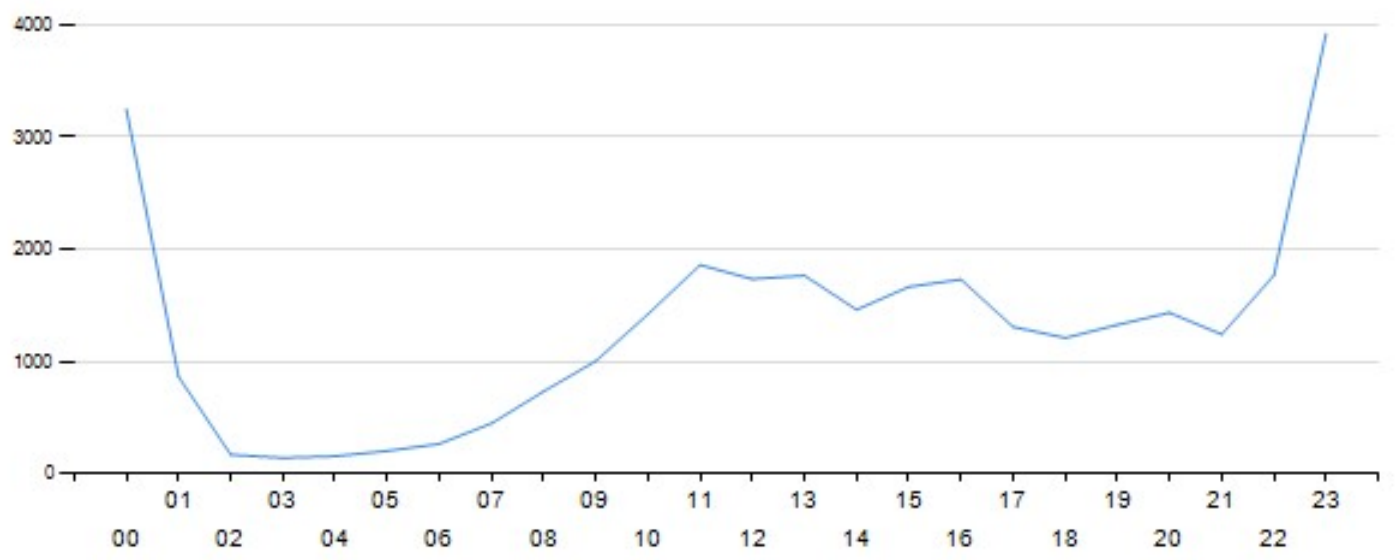

Fonte: Elaboração própria

$\mathrm{Na}$ distribuição, os horários com maior concentração de mensagens se entre $10 \mathrm{~h}$ e $11 \mathrm{~h}$ da manhã, $15 \mathrm{~h}$ e $16 \mathrm{~h}$ da tarde, com picos à noite entre $22 \mathrm{~h}$ e 23h. Tal distribuição é similar a de pesquisas que costumam analisar a audiência em mídias sociais como o Twitter. O estudo conduzido pela Sprinklr

Inf. Inf., Londrina, v. 22, n. 2, p. 420 - 436, maio/ago., 2017. http:www.uel.br/revistas/informacao/ 
(2014), por exemplo, apontou que os horários ditos "nobres" no Twitter para o ano de 2014 foi exatamente às $11 \mathrm{~h}$ da manhã e entre as $22 \mathrm{~h}$ e $23 \mathrm{~h}$ da noite.

Do total de 6.646 mensagens únicas, apenas 729 (10,96\%) foram originadas pelos candidatos, o que equivale a dizer que 5.917 delas $(89,03 \%)$ são de cidadãos/eleitores (além de perfis institucionais, empresarias e de mídia), o que indica o interesse demonstrado por estes quanto à participação política nesse período eleitoral. De acordo com Araújo (2014a, p.712)

[...] ao levarmos em consideração o volume de menções recebidas e feitas pelos candidatos e eleitores, bem como de respostas e replicações, temos uma teia de fluxos informacionais e interativos entre os atores. Compreender essa rede e visualiza-la em sua estrutura pode facilitar os estudos das campanhas online nas buscas de sua compreensão de forma complexa, dinâmica e dialógica.

Ao verificar a mediação expressa na interatividade em termos de menções e reproduções de conteúdos temos uma rede de interações que pode ser visualizada no Grafo 1.

Grafo 1. Rede de interações entre candidatos

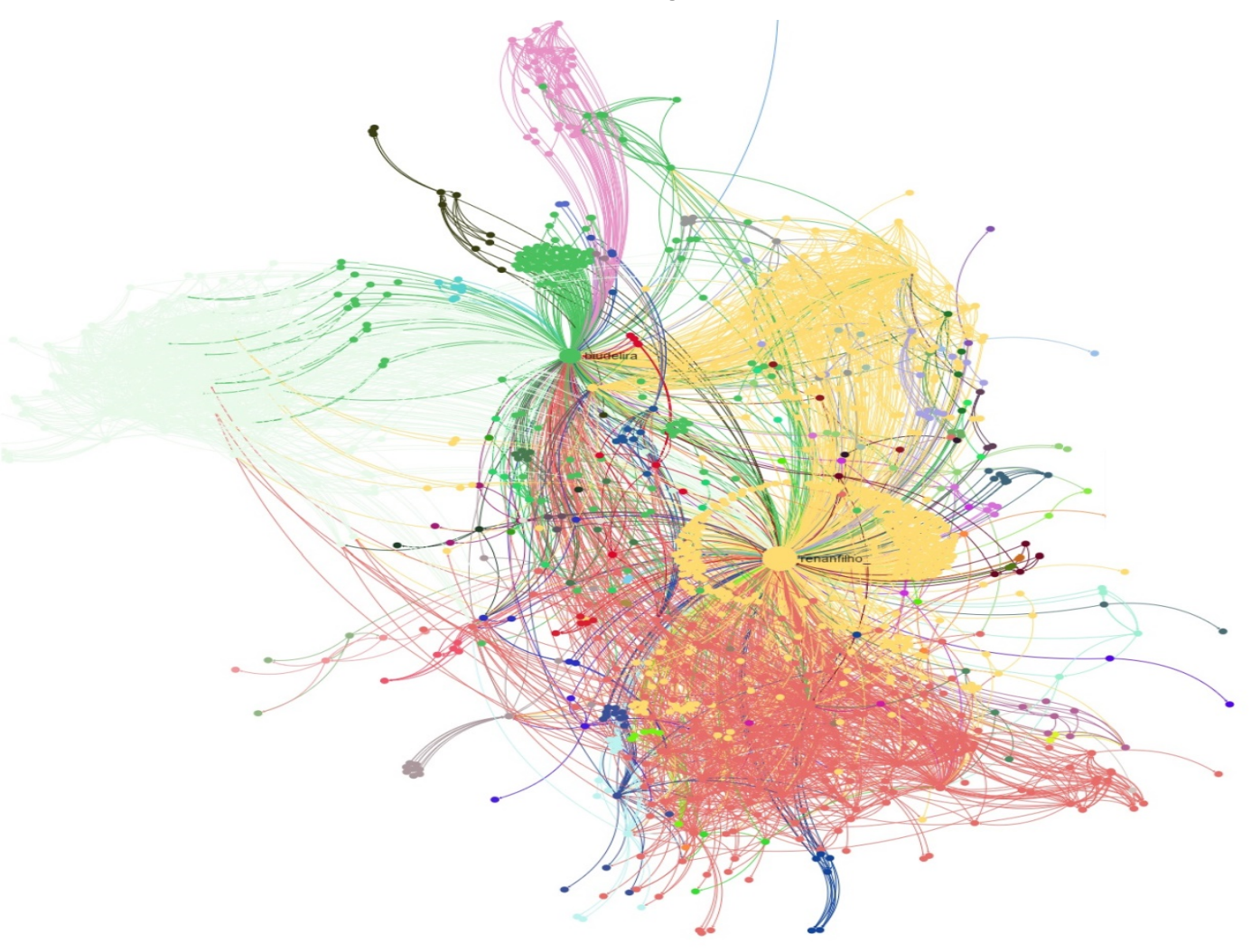

Fonte: Elaboração própria

Inf. Inf., Londrina, v. 22, n. 2, p. 420 - 436, maio/ago., 2017. http:www.uel.br/revistas/informacao/ 
No grafo, a rede formada apresenta a conexão entre os atores. Foram identificados 05 (cinco) grandes agrupamentos ou clusters que indicam maior proximidade em entre determinados usuários podendo existir um ou mais atores centrais. O número de conexões de cada cluster tem uma variação de 125 a 328 nós (usuários).

O cluster principal na cor amarela (Grafo 2) com 328 conexões está centrado na figura de Renan Filho. O último, na cor verde (Grafo 3) com 125 conexões, está centrado na figura de Biu de Lira. Os demais (vermelho = 204; amarelo $=137$; e branco gelo $=134$ ) não possuem um único usuário de destaque e é composto na sua maioria por eleitores em geral, blogueiros, jornalistas, portais de notícias locais e perfis auxiliares.

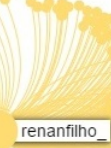

renanino.

Grafo 2. Cluster do candidato Renan Filho (PMDB)

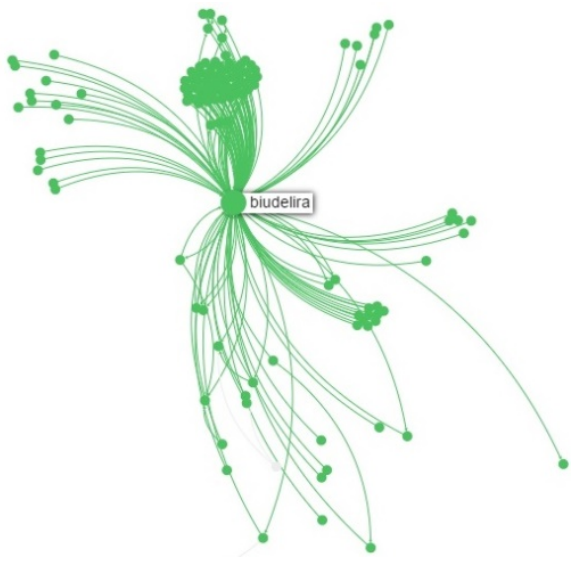

Grafo 3. Cluster do candidato Benedito de Lira (PP)

Na Análise de Redes Sociais o grau de centralidade da rede indica o padrão de interação entre os atores e no contexto da participação política em períodos eleitorais ele expressa dados referentes ao grau de entrada e saída das conexões entre o candidato e eleitores (ARAÚJO, 2014a). O candidato Renan Filho obteve o maior grau de entrada sendo mencionado 874 vezes, e possui também o perfil com maior grau de saída, mencionando outros usuários

Inf. Inf., Londrina, v. 22, n. 2, p. 420 - 436, maio/ago., 2017. 
106 vezes. O candidato e Biu de Lira, por sua vez, obteve o grau de entrada no valor de 477 com o grau de saída de 34 .

O alto desempenho de Renan Filho pode ser atribuído ao uso de perfis auxiliares, estratégia de comunicação política cada vez mais comum em campanhas eleitorais. Geralmente estes perfis tem como objetivo principal a mobilização de internautas e costumam ser mais responsivos que o perfil oficial além de apresentarem uma taxa de replicação mais alta, já que podem fazer parte de sua rotina a identificação de usuários que estão engajados com a campanha e replicar as falas sobre suas ações em prol da candidatura (REIS, 2012). Renan Filho contou com duas contas com esse tipo de atuação, o $@$ @omosRenan153 e o @RenovaAlagoas ${ }^{4}$, que por sua vez, estão entre os perfis mais ativos em termos de frequência de publicações no Twitter durante o período monitorado, postando respectivamente, 302 e 198 tweets.

As menções, respostas e reproduções possuem um papel importante no Twitter e marcam as formas de interação e comunicação dialógica nessa ferramenta. O número de respostas expressa a disposição do candidato e do eleitor ao diálogo tornando-se um indicador da interatividade adotada durante a campanha (REIS, 2012); e o número de reproduções revela o entendimento da validação e replicação de conteúdos caracterizando o uso colaborativo da ferramenta.

Os grafos apresentados expressam a mediação da informação que a mídia social promove e revela o que em parte é desconsiderado na maioria dos estudos sobre campanhas políticas online: os eleitores e suas vozes, ou seja, o elemento principal a ser observado no contexto da participação política nas campanhas.

Ao analisar o conteúdo das mensagens no que se refere à frequência encontramos com maior volume de menções de termos/assuntos: Alagoas (1.087), saúde (456), campanha (429), educação (425) e combate à violência (402).

\footnotetext{
${ }^{3}$ Ver: www.twitter.com/SomosRenan15

${ }^{4}$ Ver: www.twitter.com/RenovaAlagoas
}

Inf. Inf., Londrina, v. 22, n. 2, p. 420 - 436, maio/ago., 2017. 
As hashtags mais frequentes foram \#alagoas (399) e \#al (270) e os links mais compartilhados foram de uma mensagem com imagem sobre reestruturação da Polícia Federal: http://t.co/AIYtNCTWjU (32); e duas matérias no Portal de Notícia CadaMinuto assinadas pelo jornalista Bernardino, a primeira sobre início da campanha de Renan Filho no Agreste do Estado: http://t.co/mIC5p8zKea (15) e a segunda sobre visita do mesmo candidato a outra localidade: http://t.co/XYvjcMLGsI (15).

Quanto ao posicionamento dos eleitores verificou-se que as mensagens mais recorrentes são de adesão à campanha e de apoio aos candidatos com 1.057 tweets contra 341 de críticas feitas aos candidatos.

Consideramos que percorrer os aspectos semânticos e estruturais da conversação em rede, no contexto dos estudos sobre campanhas online, pode contribuir de forma qualitativa na compreensão das formas de interação e dos diálogos estabelecidos entre os atores (agentes políticos e eleitores) que usam sites de redes sociais como o Twitter para participação cívica.

Ao tentar compreender como foram estabelecidas as conversações entre os candidatos e os eleitores por meio do método de mapeamento de conversação em rede de Recuero (2012), seguindo a técnica de incidente crítico, percebeu-se que no período analisado não houve prolongamento da conversação estabelecida nos moldes do sequenciamento e turnos de fala, pelo menos, não que indicasse reciprocidade e persistência. Por meio do incidente crítico destacamos alguns exemplos.

Exemplo 1, no conteúdo e sequenciamento enquadrado no tema da segurança pública, temos como pares conversacionais uma eleitora que menciona o candidato chamando atenção para a conduta da PM. O turno de fala é simples com resposta do candidato:

@JessicaDinizLim @RenanFilho_Candidato, atenção para planos que envolvam a segurança pública. Alagoanos reclamam bastante da conduta insatisfatória da PM/AL 20 jul., 2014

@RenanFilho_Amiga @JessicaDinizLim, estaremos atentos pra oferecermos a $\mathrm{AL}$ um plano que possibilite reduzirmos consistentemente a violência. 20 jul., 2014

Inf. Inf., Londrina, v. 22, n. 2, p. 420 - 436, maio/ago., 2017. 
Exemplo 2, no conteúdo e sequenciamento a seguir, temos como pares conversacionais o candidato que parabeniza os comerciários de Alagoas. Com turno de fala simples recebe intervenção do eleitor @LeandoGomes_questiona o que considerou incoerente, o fato de o candidato parabenizar uma categoria e não comparecer no dia do debate na mesma:

@BiudeLira \#Biu parabeniza todos os comerciantes de \#Alagoas pelo seu dia. \#DiadoComerciante \#PlanodeGoverno \#éBiu pic.twitter.com/wLi7mCmHoT · 16 Jul., 2014.

@LeandoGomes_@BiudeLira me responde uma coisa? Como uma pessoa parabeniza o dia do comerciante e não comparece a SABATINA da FECOM? \#NaoEntendo 16 Jul., 2014.

O posicionamento do eleitor é condizente com o ideal de 'accountability discursiva' (MENDONÇA, 2008; MENDONÇA; CAL, 2012) e exemplifica a pretensão de representação do candidato sendo testada por meio do debate aberto na rede.

Por fim, o Exemplo 3, no conteúdo e sequenciamento enquadrado no tema de combate a violência, temos uma postagem do candidato Renan Filho com sua proposta de criação de Secretaria de Esportes com reposta e comentário do usuário @lulavilar expressando sua preocupação quanto ao aparelhamento do estado. Na sequência o candidato agradece a intervenção do usuário que por fim reforça sua opinião de redução da máquina pública:

@RenanFilho_ "Não sou a favor de criar muitas secretarias, mas vamos recriar a Secretaria de Esportes, fundamental no combate à violência" 15 set., 2014.

@lulavilar@ @RenanFilho_...quanto maior, mais aparelhamento. Em todo caso, parabéns por trazer a proposta para o centro do debate. É o que importa. 15 set., 2014.

@RenanFilho_Obrigado pelo reconhecimento @lulavilar . Vou manter meu foco e o objetivo de apresentar até o fim da campanha ideias e propostas. 15 set., 2014.

@lulavilar @RenanFilho_...acho que precisamos é de redução. Sepaz - por exemplo - dava para ter suas ações abrigadas em outra estrutura... 15 set., 2014. 
Os exemplos em destaque não esgotam as situações de interação entre os usuários e podem indicar o Twitter como dispositivo para trocas informacionais que possibilita maior aproximação entre candidatos e eleitores e por sua vez, uma participação política.

\section{CONCLUSÃO}

Pesquisas sobre monitoramento e métricas em mídias sociais que consideram o critério de visibilidade estimam o público alcançado tendo em vista o número de seguidores das contas analisadas. Esse tipo de critério é pouco qualitativo e mesmo que somado ao comportamento dos agentes políticos quanto à frequência e o volume de postagens, abrangência temática $\mathrm{e}$ de assuntos, bem como ao tipo de discurso, tende a mascarar a performance do candidato além de não ser suficiente para responder a questões que indicam o engajamento cívico e mediação informacional na participação política, como: quantas pessoas se envolveram no debate proposto (iniciando ou participando de um existente)? Quantas vozes se fizeram ouvir e foram respondidas? O que atrai o envolvimento em discussões? Sobre o que se quer saber quando pergunta?

Se ainda não há diálogos no Twitter certamente não é por fata de interesse dos eleitores, pois suas menções aos candidatos e participações em torno do debate político com hastags como \#eleicoes2010, \#eleicoes2012 no microblog revelam que eles se fazem presente no ambiente. Resta saber por que as campanhas não conseguem manter perfis mais dialógicos para dar ressonância à participação política que bate à porta em 140 caracteres.

Esse cenário compromete a 'accountability discursiva' (MENDONÇA; CAL, 2012) e o candidato não se põe à prova no debate público para testar sua capacidade de representar o eleitor e não expressa pré-disposição para comunicação dialógica e responsiva (DRYZEK; NIEMEYER, 2008; MAIA, 2012). Não restando muita alternativa para o eleitor a não ser aguardar respostas ou "adormecer" (Figura abaixo).

Inf. Inf., Londrina, v. 22, n. 2, p. 420 - 436, maio/ago., 2017. 


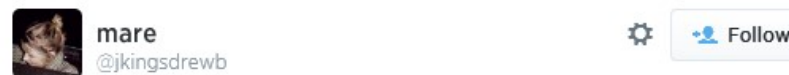

vou dormir já q o menino renan filho de deus não responde Bjs

4 Reply 47 Retweet \# Favorite ... More

2:50 AM - 21 Jul 2014

O que se percebe é que o uso de dispositivos de mediação da informação como o Twitter tem levado os usuários a esperar mais dos políticos, sobretudo em relação às estratégias de comunicação política que estes adotam, as quais são constantemente testadas e avaliadas nas dinâmicas da rede.

\section{REFERÊNCIAS}

ARAUJO, R. F.. Aspectos teórico-metodológicos para análise de campanhas eleitorais online no twitter: do mapeamento das redes às conversações. Liinc em Revista, v. 10, p. 703-725, 2014a. Disponível em:

$<$ http://liinc.revista.ibict.br/index.php/liinc/article/view/716>. Acesso em 13 ago., 2015.

ARAUJO, R. F.. Mediação da informação e participação política na web social em períodos eleitorais. In: Encontro Nacional de Pesquisa em Ciência da Informação, v.15, Belo Horizonte. Anais... Belo Horizonte: Ancib/PPGCI/ECI/UFMG, p. 1457-1477, 2014b.

DRYZEK, J.; NIEMEYER, S. Discursive representation. American Political Science Review, v.102, n.4, p. 481-493, 2008.

FRAGOSO, S.; RECUERO, R.; AMARAL, A.. Métodos de pesquisa para internet. 1. ed. Porto Alegre: Sulina, 2011.

IBOPE Inteligência [Pesquisa]. Renan Filho permanece em primeiro na disputa pelo governo de Alagoas. Eleições 2014. 11 set., 2014

JAMIL, F. P.; SAMPAIO, R.. Internet e eleições 2010 no Brasil: rupturas e continuidades nos padrões mediáticos das campanhas políticas online. Revista Galáxia, São Paulo, n. 22, p. 208-221, dez. 2011.

MAIA, R. Representação política de atores cívicos entre a imediaticidade da experiência e discursos de justificação. Rev. bras. Ci. Soc., São Paulo , v. 27, n. 78, Fev. 2012.

Inf. Inf., Londrina, v. 22, n. 2, p. 420 - 436, maio/ago., 2017. 
MENDONÇA, R. F.; CAL, D. Quem pode falar no facebook? o "autocontrole" em um grupo sobre o plebiscito acerca da divisão do estado do Pará. Revista Debates, Porto Alegre, v.6, n.3, p.109-128, set.-dez. 2012.

MENDONÇA, R. F. Representation and deliberation in civil society. Brazilian Political Science Review, Rio de Janeiro, v. 2, n. 2, p. 117-137, jul. - dez. 2008.

PIERUCCINI, I.. Ordem informacional dialógica: mediação como apropriação da informação. In: Encontro Nacional de Pesquisa em Ciência da Informação, Salvador, Bahia, ANCIB, n.8, out., 2007. Anais...Salvador, ANCIB, 2007

RECUERO, R. A conversação em rede: comunicação mediada por computador e redes sociais na Internet. Porto Alegre: Sulina, 2012.

REIS, L. dos S.. Comunicação política e a campanha online 2.0 na Bahia em 2010: uma análise da atuação dos principais candidatos ao governo do estado no Twitter e Youtube. Dissertação (Mestrado em Comunicação e Cultura Contemporâneas) - Universidade Federal da Bahia, 2012.

SAWARD, M. The representative claim. Oxford: Oxford University Press, 2010.

SPRINKLR. Horários nobres das redes sociais. 2014. Disponível em:

< https://www.sprinklr.com/pt-br/horarios-nobres-redes-sociais/ > Acesso em 10 nov., 2014.

\title{
Title
}

Twitter as information mediation device during election period: an Alagoas election analysis

\begin{abstract}
Introduction: The relational and collaborative character of the online platforms and social media offer new elements to (re) think a political communication mainly in its media. Objective: To analyze an appropriation of Twitter in its own interactives and conversations as an information mediation device between voters and the main candidates for the state government of Alagoas in the 2014 elections.

Methodology: Exploratory research with collection and systematization of data performed in the period from July 1, 2014 to October 5, 2014 through the software of monitoring of social media metrics, BrandCare. The empirical universe of 11,619 messages analyzed according to a combined approach of Social Network Analysis and Computer-mediated Conversation and their geographic, temporal distribution, by categories, as well as their own interactivity and conversation. Results: The messages posted by voters represent $89.03 \%$ of the total and candidates provided $10.96 \%$. In total, 8,101 users were identified, of which $31 \%$ are women and $69 \%$ are men. The most frequent positioning of the users is of adhesion to the campaign and of support to
\end{abstract}

Inf. Inf., Londrina, v. 22, n. 2, p. 420 - 436, maio/ago., 2017. 
the candidates. The subjects of greater recurrence of the messages are about health, education and fight to end violence. There was no prolongation of the interactions and few reciprocity and persistence. Conclusions: If there is still no dialogue on Twitter is certainly not for lack of interest of the voters, as their mentions to the candidates reveal that they are present in the environment. It remains to be seen why campaigns can not maintain more dialogic profiles to resonate with political participation.

Keywords: Political Participation. Information Mediation. Twitter. Computer-mediated conversation. Social Networking Analysis.

\section{Titulo}

Twitter como instrumento de mediación de la información en periodos electorales: análisis de las elecciones de 2014 en alagoas

\section{Resumen}

Introducción: La naturaleza relacional y colaborativa proporcionada por las plataformas en línea y los medios sociales ofrece nuevos elementos para (re)pensar la comunicación política, especialmente en lo referido a la mediación de la información. Objetivo: Analizar la apropiación de Twitter en sus aspectos interactivos y conversacionales como instrumento de mediación informativa entre los votantes y los principales candidatos para el gobierno del estado de Alagoas en las elecciones de 2014. Metodología: Investigación exploratoria basada en la recogida y sistematización de datos durante el período comprendido entre 01/07/2014 y el 05/10/2014 mediante el software para monitorización de métricas de medios sociales BrandCare. Se analiza el universo empírico de 11.619 mensajes según un enfoque combinado de Análisis de Redes Sociales y Conversación mediada por ordenador, siendo descrito en función de su distribución geográfica, temporal, y por categoría, así como por sus condiciones de interactividad y conversación. Resultado: Los mensajes enviados por los votantes representaban el $89.03 \%$ del total, frente al $10,96 \%$ de los candidatos. En total se identificaron 8.101 usuarios, de los cuales el $31 \%$ eran mujeres y el $69 \%$ hombres. La postura más común fue el apoyo a los candidatos y los temas más recurrentes de los mensajes fueron la salud, la educación y la lucha para acabar con la violencia. La red aparece fragmentada. Las interacciones no eran prolongadas y pocas de estas alcanzaron reciprocidad y persistencia. Conclusión: Si no hay diálogo en Twitter ciertamente no se debe a falta de interés por parte de los votantes, ya que con sus menciones a los candidatos han demostrado su presencia en este medio social. Cabe preguntarse por qué las campañas no logran mantener perfiles más dialógicos para dar resonancia a la participación política.

Palabras clave: Participación política. Mediación de la información. Twitter. Conversación mediada por ordenador. Análisis de Redes Sociales.

Recebido: 30.08.2017

Aceito: 30.09 .2017

Inf. Inf., Londrina, v. 22, n. 2, p. 420 - 436, maio/ago., 2017. 